\title{
Structural and magnetic properties of $\mathrm{Ni}-\mathrm{Mn}-\mathrm{Ga}$ films sputter- deposited on cube-textured polycrystalline substrate
}

\author{
V.A. Chernenko ${ }^{1,2, a}$, P. Bassani ${ }^{3}$, R. Lopez Anton ${ }^{4}$, S. Besseghini ${ }^{3}$, J.M. Barandiaran ${ }^{1}$, A. Tuissi ${ }^{3}$, I. Orue ${ }^{1}$, \\ P. Lazpita ${ }^{1}$, M. Ohtsuka ${ }^{5}$ \\ ${ }^{1}$ University of Basque Country, Dept. Electricidad y Electronica, PO Box 644, E-48080, Bilbao, Spain \\ ${ }^{2}$ IKERBASQUE, Basque Foundation for Science, 48011, Bilbao, Spain \\ ${ }^{3}$ CNR-IENI, C.Promessi Sposi, 29, Lecco 23900, Italy \\ ${ }^{4}$ Universidad de Castilla La Mancha, Dep.Física Aplicada,13071 Ciudad Real, Spain \\ ${ }^{5}$ IMRAM, Tohoku University, Sendai 980-8577, Japan
}

\begin{abstract}
Texture, magnetic and micromagnetic properties of the martensitic thin films with different thicknesses prepared by magnetron sputtering of $\mathrm{Ni}_{52} \mathrm{Mn}_{24} \mathrm{Ga}_{24}$ target on paramagnetic Ni-Cr-W cube-textured thin tape are studied. The films exhibit 220 -fiber texture. The texture features together with a large magnetocrystalline anisotropy lead to the conclusion about particular domain structure.
\end{abstract}

\section{Introduction}

Ni-Mn-Ga ferromagnetic shape memory alloys (FSMAs) show large magnetoplasticity and strain-induced change of magnetization, both effects are due to the magnetic field- or stress-induced twin rearrangements as a result of the high twin boundary mobility in a magnetoelastic matrix (see [1] and references therein). Thin film technology of these materials is currently under development in order to extend their functionality to the submicron scale [1-12]. Properties of Ni-Mn-Ga films depend very much on the substrate nature, surface roughness, film thickness and technological details of their production. The transformation behavior and magnetic characteristics of these films are controlled by crystallography, substructure and residual stress [1-12]. The substrate nature and its temperature during deposition are seemingly the main factors determining whether single crystalline or textured polycrystalline state of film is formed. It was found that Ni-Mn-Ga films deposited at room temperature on the alumina ceramic [4], Mo foil [2,3,9], $\mathrm{MgO}(100)$ [6] or $\mathrm{Si}(100)$ [7] wafers are polycrystalline and exhibit predominantly 220 fiber texture after subsequent heat-treatment at $1070 \mathrm{~K}$, whereas these films demonstrated an epitaxial growth during the deposition on heated single crystalline substrates such as $\mathrm{Al}_{2} \mathrm{O}_{3}(11-20)$ [5], $\mathrm{MgO}(100)[5,8,12]$ or $\mathrm{SrTiO}_{3}(100)$ [10].

The Ni-Mn-Ga/substrate thin film composites, where the substrate is a micrometer-sized thin metallic foil are promising materials for microactuator applications [2]. In this work, we extend the studies of Ni-Mn-Ga thin films by utilizing a polycrystalline Ni-Cr-W cube-textured tape as the thin metallic foil substrate. Such tapes are especially designed for high-temperature superconductor technologies [13]. Hereafter we describe the details of preparation of $\mathrm{Ni}-\mathrm{Mn}-\mathrm{Ga} / \mathrm{Ni}-\mathrm{Cr}-\mathrm{W}$ thin film composites and the results of their structural and magnetic characterization.

\section{Experimental}

Polycrystalline thin films with thicknesses of $0.6,1.0$ and $2.0 \mu \mathrm{m}$ were fabricated at $\mathrm{T}=320 \mathrm{~K}$ by radio-frequency (r.f.) magnetron sputtering of a $\mathrm{Ni}_{52} \mathrm{Mn}_{24} \mathrm{Ga}_{24}$ target on rectangular plates of paramagnetic $\mathrm{Ni}-\mathrm{Cr}-\mathrm{W}$ cubetextured $80 \mu \mathrm{m}$-thick tape with all $\{100\}$ edges. Such a tape normally serves as a substrate for deposition of the high-temperature superconducting ceramics. The r.f. power of sputtering machine (Shibaura, CFS-4ES) was kept at $200 \mathrm{~W}$. The film composites were annealed at $1073 \mathrm{~K}$ for $1 \mathrm{~h}$. in vacuum of $2 \times 10^{-4} \mathrm{~Pa}$. The surface roughness,

a e-mail: Vladimir.chernenko@gmail.com

This is an Open Access article distributed under the terms of the Creative Commons Attribution-Noncommercial License (http://creativecommons.org/licenses/by-nc/3.0/), which permits unrestricted use, distribution, and reproduction in any noncommercial medium, provided the original work is properly cited. 
$\mathrm{Ra}$, of the tape was measured using surface profile measuring system ULVAC, Dektak3ST to be about $30 \mathrm{~nm}$. In the present work, all the conditions of films preparation including the parameters of sputtering, target and subsequent annealing were identical to our previous studies [2-4,6,7,9]. These studies have shown that the target and annealing used facilitate the formation of a modulated pseudo-orthorhombic ferromagnetic martensitic phase at room temperature. The XRPD $\theta-2 \theta$ profiles obtained in this work (Rigaku RINT2200 diffractometer, $\mathrm{CuK}_{\alpha}$ radiation) contain only one intense peak at the 220 line position, overlapped with several weaker peaks which number depends on the film thickness. Although rigorous analysis of such XRPD patterns is impossible, in analogy with previous works $[3,7,9]$, one can deduce that the films have 220 fiber texture and the martensitic phase has a modulated lattice.

The texture details of films have been checked by electron backscattering diffraction analysis (EBSD). The EBSD data have the advantage that they can resolve the orientations of two or more phases separately, which is not possible for the X-ray texture analysis.

To detect the martensitic transformation (MT) and Curie temperature of the films, the magnetization at 20 Oe versus temperature was recorded by a SQUID magnetometer (Quantum Design MPMS). In-plane and out-ofplane magnetization loops at room temperature were also recorded. The magnetic signal from the substrate was recorded separately in order to correct the data. Minor $\mathrm{M}(\mathrm{H})$ loops were measured in different in-plane directions by a magneto-optical Kerr effect (MOKE). The magnetic force microscopy, MFM, and atomic force microscopy, AFM, measurements were performed with a Digital Instrument 3100 AFM/MFM probe microscope. Topographic (height contrast) and magnetic (phase contrast) images were obtained in tapping and tapping-lift mode using standard non-magnetic and magnetic tips. Magnetized $\mathrm{CoCr}$ coated etched silicon probe magnetic tips with resonant frequency $70 \mathrm{kHz}$ were used. The lift scan height was in the range 50-120 nm depending on the sample. More experimental details can be found elsewhere (see $[3,6]$ and references therein).

\section{Results and discussion}

The examples of EBSD microstructures and pole figures are shown in Fig.1 for the pure substrate (a) and
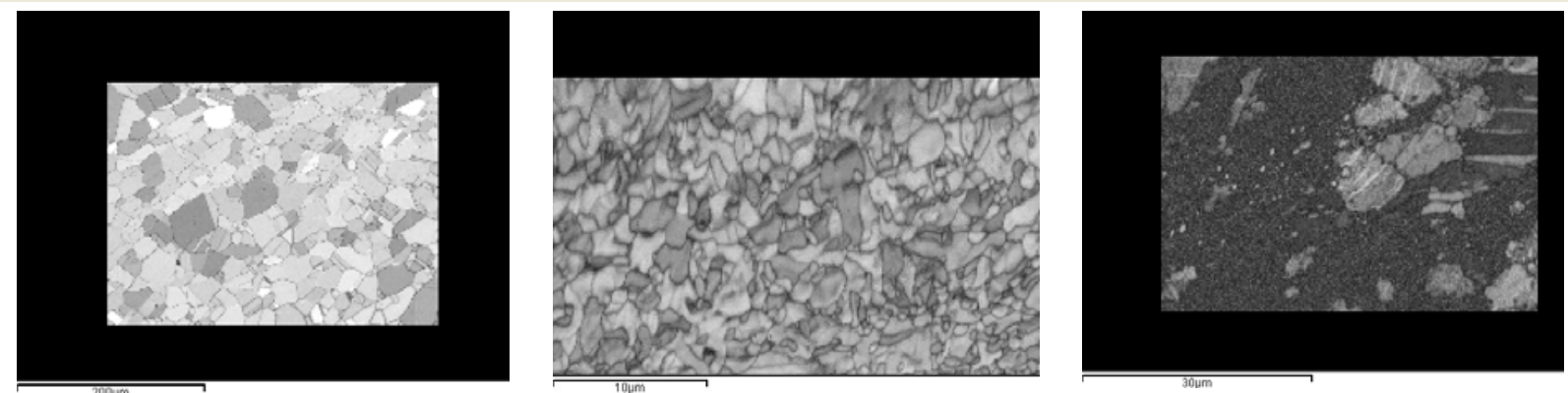

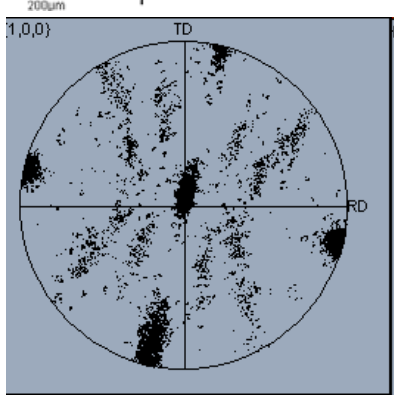

a)

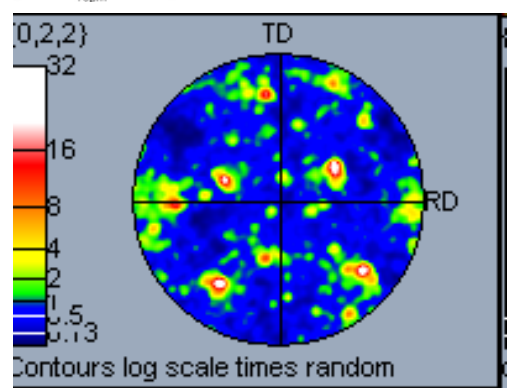

b)

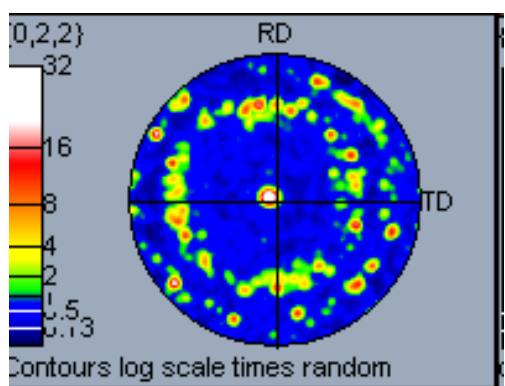

c)

Fig. 1. The microstructures (upper images) and pole figures (bottom images) obtained by EBSD measurements of pure substrate (a) and Ni-Mn-Ga thin films with thicknesses of $0.6 \mu \mathrm{m}$ (b) and $2.0 \mu \mathrm{m}$ (c). The images are obtained with different magnifications shown with the scale bars of 200,10 and $30 \mu \mathrm{m}$ for microstructures (a)-(c), respectively.

Ni-Mn-Ga/substrate film composites with two film thicknesses (b,c). Obviously, the grain structure and average grain size of the films do not match those of the substrate: according to Fig.1, the average grain size of the film is about one order of magnitude smaller than the one of substrate. The Ni-Mn-Ga films deposited on single crystalline substrates with the same procedure described in this work, also show a polycrystalline state [6,7]. Nevertheless, in all these cases, the most important issue was that the films are crystallographically textured, and the texture of polycrystalline films gives rise to a certain martensitic twin structure. The latter, in turn, can be a 
prerequisite of the occurrence of perpendicular magnetic anisotropy being one of the most important properties for applications [2-4,6]. The poles figures in Fig.1 clearly demonstrate the cube-texture of the substrate (a), whereas the 1.0 and $2.0 \mu \mathrm{m}$-thick films have a well-developed 220 fiber texture as evidenced from Fig.1(c). Some non-defined texture components are observed for the film with thickness of $0.6 \mu \mathrm{m}$, Fig. 1(b). As a whole, pole figures are in line with XRPD results mentioned in Sec.1.

In general, the structural and ferromagnetic transformations in the heat-treated well-ordered Heusler alloys are readily detected by the anomalies on the temperature dependence of low-field magnetization $[7,8]$.

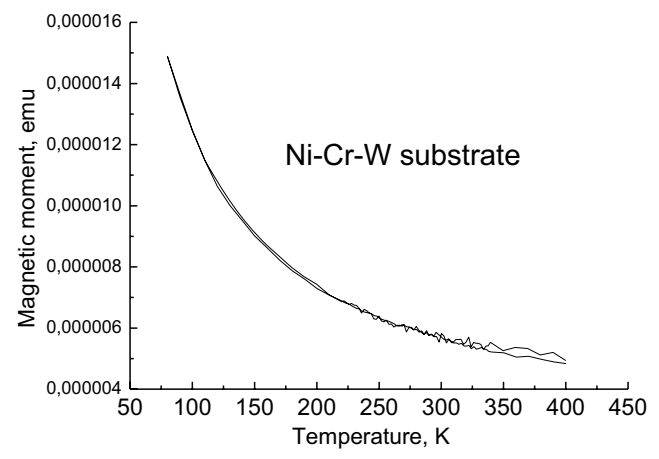

a)

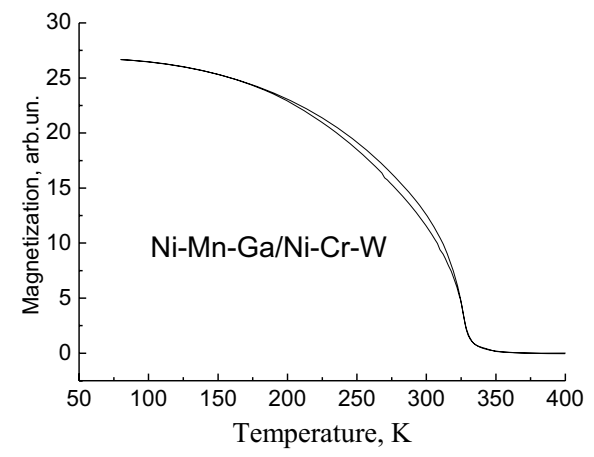

b)

Fig. 2. Magnetisation curves measured at $20 \mathrm{Oe}$ as a function of temperature for pure Ni-Cr-W substrate (a) and Ni-Mn$\mathrm{Ga} /$ substrate film composite with film thickness of $1.0 \mu \mathrm{m}$.

This is demonstrated by the experimental curves in Fig.2. Whereas the pure substrate exhibits paramagnetic behavior, Fig.2(a), the Ni-Mn-Ga/Ni-Cr-W thin film composites show a typical well-pronounced hysteretic anomaly which reflects the presence of the martensitic transformation (MT) and the characteristic anomaly at $330 \mathrm{~K}$ which is an unequivocal signature of the Curie temperature, Fig.2(b). Due to the perfectly reversible character of the martensitic transformation and the small temperature hysteresis width, it is hard to specify characteristic temperatures of MT by the curves in Fig.2(b). Furthermore, similar to the situation with the

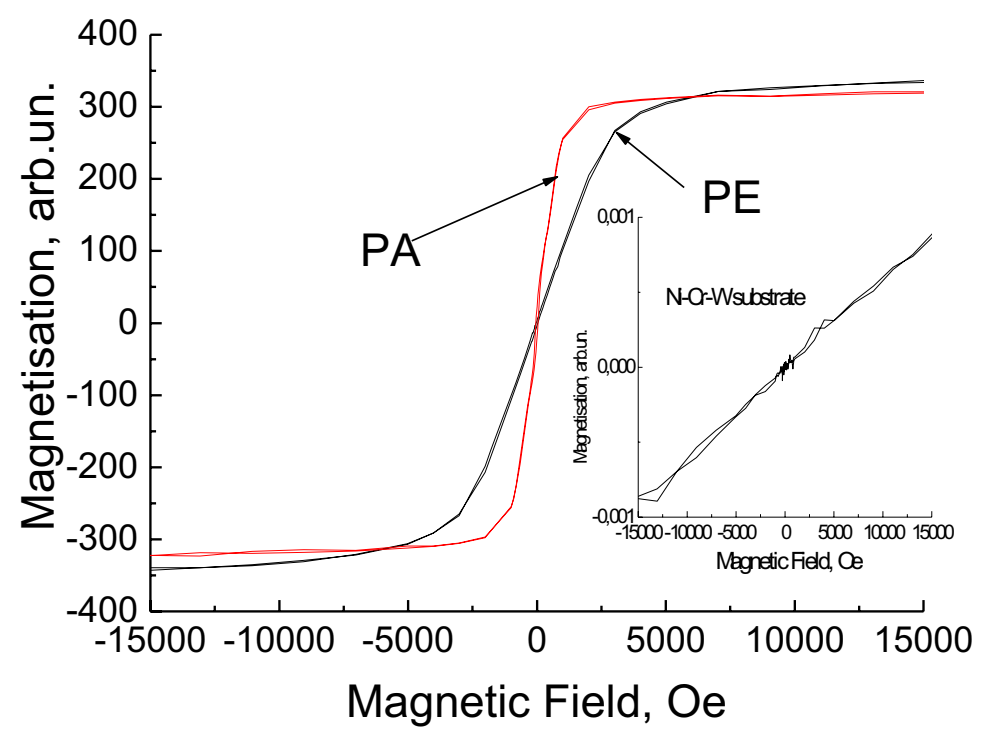

Fig. 3. Typical examples of the change of magnetization of $\mathrm{Ni}-\mathrm{Mn}-\mathrm{Ga} / \mathrm{Ni}-\mathrm{Cr}-\mathrm{W}$ thin film composite as a function of the magnetic field measured at room temperature in the perpendicular to film plane direction (PE) and parallel to it (PA). The film thickness is $2 \mu \mathrm{m}$. The Inset shows magnetisation versus magnetic field behaviour of substrate.

$\mathrm{Ni}-\mathrm{Mn}-\mathrm{Ga} / \mathrm{MgO}(100)$ film composites [6], we did not find within the experimental limitations any film thickness dependence of both the Curie temperature and MT temperature. 
Fig. 3 shows examples of magnetization loops measured in the perpendicular (PE) to film plane direction and parallel (PA) to it. The magnetization behaviour of the pure substrate shown in the Inset is the paramagnetic one. The magnetization curves of the films show typical values of the saturation magnetic field to be equal to about $7.5 \mathrm{kOe}$ and $2.0 \mathrm{kOe}$ in perpendicular and parallel measurements, respectively, for all the films. Note that coercive field $\mathrm{H}_{\mathrm{c}} \approx 50$ Oe was approximately the same for in-plane and out-plane configurations. Precise MOKE measurements of partial magnetization loops have been carried out in the different in-plane directions in attempt to find out an in-plane component of the magnetic anisotropy in the films. Such anisotropy component was not observed, that is consistent with the fiber texture of the films.

Fig. 4 shows the magnetic domain structure of $2.0 \mu \mathrm{m}$-thick film imaged at zero applied field and room temperature. Whereas a worm-like domain pattern similar to that shown in Fig. 4 is also revealed for the $1.0 \mu \mathrm{m}-$

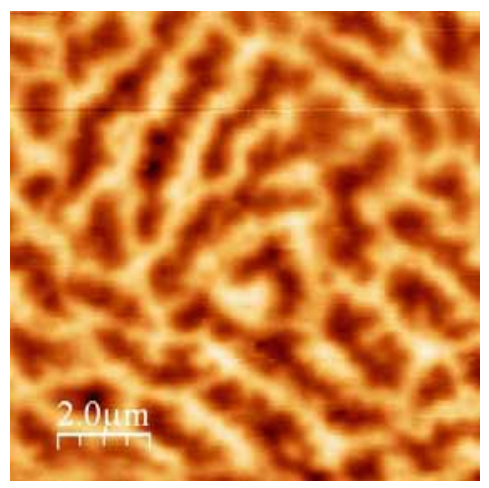

Fig. 4. MFM image of the domain pattern for NiMnGa/Ni-Cr-W martensitic film composite. The film thickness is equal to $2.0 \mu \mathrm{m}$. The frame size of image is $10 \times 10 \mu \mathrm{m}^{2}$.

thick film,the MFM images were very irregular and fuzzy for the $0.6 \mu \mathrm{m}$ film. The latter facts can be attributed to the influence of the aforementioned specific texture properties observed for this film.

Domain patterns as such shown in Fig.4 are normally produced by the perpendicular component of the macroscopic magnetization directed up and down, perpendicular to the film surface. This component is caused by the 220 fiber texture and a preferable orientation of martensitic variants with easy-magnetization c-axis inclined to the film plane by $45^{\circ}[3,4,6]$.

The perpendicular magnetic anisotropy energy of the studied textured films consists of several competitive constituents such as magnetocrystalline anisotropy, stress-induced anisotropy and magnetostatic energy due to the film shape. Numerical estimations made for films of the same Ni-Mn-Ga composition, deposited on different substrates, show that the sum of the former two anisotropies is essentially larger than the magnetostatic contribution $[3,6,14]$. In analogy to the previously studied films, one can assume a definite actuation capability of the present film composites. As a further step to demonstrate that the actuation really occurs, we are currently measuring the magnetostrain as described in Ref.[2].

In summary, a new series of martensitic Ni-Mn-Ga films deposited on Ni-Cr-W cube-textured substrate have been fabricated. The basic microstructural and magnetic characterization of this series of film composites revealed their potential for the magnetic microactuator applications.

VAC is grateful to Basque Government, Department of Education, for financial support (project IT-347-07).

\section{References}

[1] Advances in Shape Memory Materials. Ferromagnetic shape memory alloys. Edited by V.A. Chernenko (Mat.Sci Forum, 583, TTP, Switzerland, 2008).

[2] M.Kohl, A.Agarwal, V.A.Chernenko, M.Ohtsuka, K.Seemann, Mat. Sci. Eng. A 438-440, 940 (2006).

[3] V.A.Chernenko, R.Lopez Anton, M.Kohl, J.M.Barandiaran, M.Ohtsuka, I.Orue, S.Besseghini, Acta Mat. 54, 5461 (2006).

[4] V.A.Chernenko, M.Hagler, P.Müllner, V.M.Kniazkyi, V.A.L'vov, M. Ohtsuka, S.Besseghini, J. Appl. Phys. 101, 053909 (2007).

[5] G. Jakob, T. Eichhorn, M. Kallmayer, H. J. Elmers, Phys. Rev. B 76,174407 (2007).

[6] V.A. Chernenko, R. Lopez Anton, J.M. Barandiaran, I. Orue, S. Besseghini, M. Ohtsuka, A. Gambardella, IEEE Trans. Magn. 44, 3040 (2008).

[7] S.Besseghini, A. Gambardella, V.A. Chernenko, M. Hagler, C. Pohl, P. Müllner, M. Ohtsuka, S. Doyle, Eur. Phys. J. Special Topics 158,179 (2008). 
[8] F. Khelfaoui, M. Kohl, J. Buschbeck, O. Heczko, S. Fähler, L. Schultz, Eur. Phys. J. Special Topics, 158, 167 (2008).

[9] V.A. Chernenko, S. Doyle, M. Kohl, P. Müllner, S. Besseghini, M. Ohtsuka, Z. Kristallogr. Suppl. 26, 229 (2007).

[10] O. Heczko, M. Thomas, J. Buschbeck, L. Schultz, S. Fähler, Appl. Phys. Lett. 92, 072502(2008).

[11] M. Thomas, O. Heczko, J. Buschbeck, U. K. Rößler, J. McCord, N. Scheerbaum, L. Schultz, S. Fähler, NJP 10, 023040 (2008).

[12] M. Thomas, O. Heczko, J. Buschbeck, L. Schultz, S. Fähler, Appl.Phys. Lett. 92, 192515 (2008).

[13] M.Major, R.I. Tomov, B. A. Glowacki, A.M. Campbell, C.E. Oberly, IEEE Trans. Appl. Superconduct. 13, 3626 (2003).

[14] M. Hagler, V. A. Chernenko, M. Ohtsuka, S. Besseghini, P. Müllner, "Magnetic anisotropy, stress, and martensitic transformation in Ni-Mn-Ga thin films on Si(100) wafer", Mater. Res. Soc. Symp. Proc. 998, 2007 Materials Research Society 0998-J06-09. 